\title{
ENTRE LA RUTINA, EL CAMBIO Y LA TRANSICIÓN: EL INVOLUCRAMIENTO POLÍTICO EN LA MILITANCIA JUVENIL DE ORGANIZACIONES POLÍTICO PARTIDARIAS EN RESISTENCIA (CHACO)
}

\author{
Between the routine, the change, and the transition: The political involvement \\ within the youth militancy of political party organizations in Resistencia (Chaco)
}

\author{
Marina Campusano* \\ https://orcid.org/0000-0002-5857-9858
}

\section{Resumen}

El presente trabajo indaga en los procesos que fueron generando un mayor involucramiento político de jóvenes militantes en organizaciones político partidarias de la ciudad de Resistencia (Chaco). Se trata de un trabajo desde un enfoque cualitativo, en donde se privilegia la mirada de los actores, es por ello que, a partir de entrevistas semiestructuradas, revisamos los momentos centrales de sus itinerarios de militancia. La reconstrucción y análisis de las trayectorias de los y las militantes desde la sociología del compromiso militante nos permitió dar cuenta de las variadas formas en que se produce un mayor involucramiento, tanto con la agrupación de pertenencia como con la práctica política. Nos detenemos en este trabajo, en dos procesos, el rol de la "orgánica" en la estabilización de la militancia a través de la construcción de una rutina militante, por un lado, y los movimientos de cambio en los trayectos que denominamos hitos transicionales, por otro, los cuales nos permitieron acercarnos a la práctica política en clave generacional.

$$
<\text { Involucramiento }><\text { Jóvenes }><\text { Militancia }><\text { Rutina militante }>
$$

\begin{abstract}
This paper explores the processes which generated a greater commitment and political involvement of young militants in political organizations of the city of Resistencia (Chaco). From a qualitative perspective, the actors viewpoint has been privileged. Based on semi-structured interviews, we review the central moments of their militancy itineraries. Reconstruction and analysis of the militants' trajectories, from the point of view of the sociology of the militant compromise, allowed us to understand the ways in which greater involvement occurs, both in groups of belonging and in political practice. Thus, in order to analyze political practice in generational key, we focus on two processes the role of the "orgánica" in the stabilization of militancy through the construction of a militant routine, on the one hand, and the movements of change of trajectories called transitional milestones, on the other.
\end{abstract}

$<$ Engagement $><$ Young people $><$ Activism $><$ Militant routine $>$

Recibido: 22/02/2019

Aceptado: 16/05/2019

\footnotetext{
* Centro de Estudios Sociales, Universidad Nacional del Nordeste (CES-UNNE), docente-investigadora, Facultad de Humanidades (UNNE), Argentina, marinacampusa@gmail.com
} 
Campusano. Entre la rutina, el cambio y la transición: El involucramiento político en la militancia juvenil de...

\section{Introducción}

En las páginas que siguen analizaremos el proceso e involucramiento político de jóvenes que militan en organizaciones político partidarias ${ }^{1}$ de la ciudad de Resistencia Chaco (Argentina). Nos preguntamos acerca de las formas en que la práctica política pasa a ser una actividad importante para los individuos, a través de qué procesos, personajes y momentos los y las militantes de un espacio político determinado van sedimentando su vínculo tanto con el mismo como con la política. Este trabajo parte de los resultados de una tesis doctoral que tuvo por objetivo analizar el itinerario de militancia de jóvenes al interior de las agrupaciones políticas y sus diversos recorridos en las mismas, como forma de reconstruir y comprender las variadas formas y factores que influyen en la construcción del compromiso político.

Es así que dimos cuenta, como especifica Agricoliansky (2017, p. 5), que el proceso de involucramiento que genera un mayor compromiso en una actividad social no se produce "como una curva continua, sino como una serie de líneas quebradas que representan 'secuencias' cuyas etapas produce, cada una, las condiciones de posibilidad de la siguiente". Al tratar de reconstruir ese proceso, que no se produce de manera lineal u ordenada, nos introdujimos en terrenos que se nos presentaban como menos perceptibles fácilmente. Es decir, en este artículo nos ubicamos en la etapa en la que las y los militantes ya se encuentran integrados a las agrupaciones y por lo tanto refieren a prácticas más estables y naturalizadas en su militancia. Demandó entonces ir desentramando en sus narraciones estos ensambles, donde se cruzan necesariamente los órdenes y rutinas que reflejan, a su vez, una mayor o menor institucionalización partidaria (Fretel, 2011).

Indagamos en la complejidad de los espacios y sus militantes para dar cuenta de las variadas formas en que se produce el compromiso político. Planteamos para ello el abordaje a través de categorías que nos marcan estados diferenciados, como pueden ser la rutina, los cambios y la transición, ${ }^{2}$ pensando que tales procesos de involucramiento pueden ser muy visibles y hasta previsibles, y a la vez pasar desapercibidos al solaparse en las prácticas más cotidianas y naturalizadas de la militancia.

El artículo se organiza en tres momentos, en el primero exponemos los conceptos generales y aspectos metodológicos que guiaron el trabajo. Continuamos con la presentación de la rutina militante como forma en la que se estabiliza la práctica política en las agrupaciones, en tanto delimitación de roles y actividades como forma de aprendizaje de los valores e identidad partidaria, con especial énfasis en el papel que cumple la "orgánica” en la conformación de la misma. En el tercer apartado, damos cuenta de los momentos de cambio en los trayectos a través del desarrollo de lo que

\footnotetext{
1 Nos referimos a organizaciones político partidarias en tanto que las agrupaciones analizadas no se constituyen como partidos políticos propiamente dichos, independientemente de que se muevan en un mismo espacio político y adopten muchas de sus prácticas y acciones.

2 Aparecen en cursiva los conceptos o categorías que cobran relevancia para la autora, mientras que en cursiva y entre comillas estarán las voces nativas.
} 
denominamos hitos transicionales; los mismos nos acercan a comprender la militancia juvenil en clave generacional.

\section{Aspectos conceptuales y metodológicos}

En este trabajo adoptamos un diseño metodológico de acuerdo al enfoque cualitativo que permitió la producción de datos descriptivos a partir de la perspectiva de los actores, es así que nos situamos dentro del paradigma interpretativo (Vasilachis de Gialdino, 2007). El objetivo que guio la investigación fue analizar las experiencias de las y los militantes en diferentes tramos de su recorrido en las agrupaciones, a modo de reconstruir sus trayectorias. De esta forma, la organización del trabajo de campo ${ }^{3}$ partió de un relevamiento para identificar y elegir las organizaciones; optamos por aquellas en las que observamos una mayor presencia juvenil y que, a su vez, se correspondían con las fuerzas políticas más representativas ${ }^{4}$ y diversas en el arco ideológico.

Presentamos casos de jóvenes que integran La Cámpora ${ }^{5}$ (LC), la Juventud Radical (JR) perteneciente al partido Unión Cívica Radical ${ }^{6}$ (UCR), el Partido Obrero ${ }^{7}$ (PO) y Acción Chaqueña ${ }^{8}$ (ACHA). Consideramos que las diferencias ideológicas y organizativas que observamos entre las distintas agrupaciones nos permitió aportar una mayor riqueza al análisis. Tras la aplicación de una encuesta para delimitar los perfiles de las y los militantes y en conversación con las y los referentes de los espacios, llevamos adelante la selección intencional de las personas a entrevistar, siguiendo criterios como antigüedad, género, roles orgánicos ocupados, entre otros. Entrevistamos entonces a un total de veintiún militantes.

Este artículo, como adelantamos, se desprende de un trabajo mayor donde analizamos y reconstruimos etapas del recorrido militante. Nos detendremos en el momento posterior al ingreso de los y las jóvenes a la agrupación donde el eje central

3 El trabajo de campo se llevó adelante desde el año 2015 hasta el año 2017.

4 Tuvimos en cuenta los datos de los últimos períodos eleccionarios, teniendo presente a las fuerzas con más caudal de votos.

5 La Cámpora es una agrupación política argentina de línea peronista fundada, a nivel nacional, en 2006, vinculada al kirchnerismo en apoyo a las gestiones de Néstor Kirchner y las posteriores presidencias de Cristina Fernández. En Chaco, aparece aproximadamente en 2008, agrupando a organizaciones peronistas y kirchneristas locales y vinculadas a movimientos nacionales. Actualmente, se encuentra cercana a la gestión del intendente de la ciudad de Resistencia Jorge "Coqui" Capitanich.

6 La Unión Cívica radical es un partido político argentino fundado nacionalmente en 1891. En el Chaco, tiene sus orígenes en 1913. No obstante, es uno de los más antiguos de la provincia y a la cual gobernó durante tres períodos consecutivos 1995-1999, 1999-2003 y 2003-2007. Entre sus principales figuras podemos nombrar a los exgobernadores Ángel Rozas y Roy Nikish y la ex intendenta de la ciudad de Resistencia Aida Ayala.

7 Es un partido político argentino que nace, a nivel nacional, en 1964, de orientación trotskista y socialista. En la provincia, tiene sus orígenes en 1984, con una fuerte participación estudiantil universitaria. Más adelante, en los noventa, virará su conformación más obrera y en alianza con movimientos sociales. Una de sus principales figuras es Aurelio Díaz, actual diputado provincial.

8 ACHA es un partido político provincial creado en 1988 por José Ruiz Palacios, un militar cordobés, que fue gobernador de facto de la provincia durante la última dictadura militar. En 1991, el partido gana ajustadamente las elecciones llevando como gobernador a Rolando Taugüinas. 
lo constituye la pregunta por la evolución del involucramiento político. Entendemos a este último como un proceso que lleva a una instancia de mayor compromiso de los y las militantes para con la organización y su práctica política. Es decir, nos interesa analizar cómo la militancia comienza a adquirir para los y las jóvenes una mayor relevancia en sus vidas, que de acuerdo con los procesos y momentos en los trayectos que fueron identificando, puede tomar formas variadas, en tanto comportamiento humano consistente (Becker, 1960). La perspectiva que adoptamos se enmarca en los aportes de la sociología política francesa del compromiso militante (Pudal, 2011; Agrikoliansky, 2001; Fillieule, 2015), cuyos fundamentos teóricos se extraen del interaccionismo simbólico (Goffman, 1968; Hughes, 1996). Además, nos valimos de herramientas provenientes de trabajos de la ciencia política, la antropología y la sociología política que fueron vitales para el abordaje y comprensión de nuestro trabajo.

Desde esta perspectiva, se tiene en cuenta la trayectoria militante no como el resultado de una estrategia preestablecida, sino como el resultado de una serie de ajustes, en donde el involucramiento político hacia instancias de mayor compromiso, dirá Agrikoliansky (2001, p. 34) "es a menudo el resultado de la conjunción de eventos que son impredecibles por los agentes (la oportunidad de acceder a un puesto de responsabilidad, una situación electoral favorable) y que resulta de la interferencia entre la vida pública y la vida privada". Es por ello que el involucramiento debe ser analizado como un proceso, en donde el compromiso con la práctica política, al igual que con la doctrina del espacio, se forja con el tiempo y la experiencia.

En este sentido, la noción de carrera que Becker (2009) retoma de Hughes, cobra relevancia para nuestro trabajo dado que nos permitió analizar de manera procesual los diferentes comportamientos en tanto modelos secuenciales. Este abordaje fue elaborado en principio por Hughes para estudios laborales con el propósito de identificar "la secuencia de movimientos de un puesto de trabajo a otro que hace un individuo que se desplaza dentro del sistema ocupacional" (Becker, 2009, p. 43). A partir de allí, a través del concepto de "contingencia ocupacional", podía analizar los factores que influyen en tales cambios, ya sean objetivos en cuanto a la estructura social o aquellos que reflejan sus cambios subjetivos con respecto a motivaciones, esquemas de comprensión y puntos de vista del individuo.

Hughes (1937) ha definido carrera, 'objetivamente como una serie de jerarquías y cargos claramente definidos... las consecuencias típicas de la posición, los logros, las responsabilidades e incluso las aventuras (...) Subjetivamente, una carrera es la perspectiva móvil desde la cual el individuo ve su propia vida como un todo e interpreta el significado de sus diversos atributos, acciones y aquello que le sucede' (Becker, 2009, p. 123).

Estos aportes le permitieron a Becker adoptar tal enfoque para estudiar las carreras en la desviación, y a su vez ese movimiento inició el desarrollo de una 
perspectiva que fue continuada por sociólogos franceses interesados en abordar los procesos de compromiso político. Ahora bien, en el caso de jóvenes que participan en organizaciones político partidarias damos cuenta que en los trayectos que van desarrollando en términos de carrera política es difícil evidenciar secuencias que revelen formas de involucramiento siguiendo una serie de jerarquías o cargos definidos de manera fija o institucional al estilo de Hughes. En cambio, se producen mudanzas de posiciones objetivas en tanto movilidad en la estructura partidaria, como así también aquellos cambios a nivel subjetivo con respecto a las modificaciones en su percepción en cuanto a la práctica política y su propia militancia, ya sea a partir de una nueva posición o no.

El centro de nuestra atención está en los cambios o procesos de cambio a través de los que podemos identificar un mayor involucramiento. De acuerdo con las narraciones de los y las militantes pudimos dar cuenta, por un lado, de la estabilización de la práctica política a través de la construcción y seguimiento de una rutina, donde intervienen factores y actores del propio espacio y aquellas estrategias que los y las militantes van articulando. Por otro lado, distinguimos los procesos de cambio a través de los movimientos en los itinerarios, ya sean entendidos como ascenso o transición hacia una nueva posición -objetiva y/o subjetiva. De esta manera, podemos evidenciar las diferentes etapas y procesos en donde la militancia, a través de momentos o en secuencias, va generando avances y también retracciones en el involucramiento que se marcan en forma de hitos en clave generacional. Nos muestran la práctica política de jóvenes en tanto experiencia compartida por grupos históricos determinados.

En el análisis indagamos los factores que intervienen tanto para estabilizar la práctica política como aquellos presentes en los momentos de movimiento y cambio. Los procesos develaron la diversidad de los factores que pueden ser contextuales, individuales o los que responden a la estructura e identidad política de la propia organización. A su vez, al reconstruir esos estados, presentamos los obstáculos que se les van revelando en la práctica, las retribuciones y las estrategias que logran delimitar.

\section{La rutina militante: su estabilización orgánica}

En este apartado abordamos un aspecto que a menudo pasa desapercibido: la rutina militante. Una vez que los y las jóvenes se incorporan a una agrupación atraviesan una serie de procesos de aprendizaje y entrenamiento para formarse e incorporar las lógicas de la práctica política en el espacio al igual que sus valores y rasgos de acuerdo a su identidad política. Es así que se incorporan a un frente o área de la organización, según la estructura organizativa del partido, donde asumen una serie de actividades y roles como parte de ese ámbito para asegurar su funcionamiento. Es reconocible en las narrativas sobre este momento una reflexividad en cuanto a las prácticas que llevan adelante en función de lo que expresan como un "proyecto político" mayor o del "modelo de país" que quieren construir, en línea con la identidad política del espacio. Además, a nivel personal se reconocen más "cómodos" o "aptos" en cuanto a los 
Campusano. Entre la rutina, el cambio y la transición: El involucramiento político en la militancia juvenil de...

ámbitos y tipos de prácticas en que se ven envueltos, más habituados e involucrados con la praxis política.

En esta sección nos interesa indagar en las maneras en que se produce esa habituación, es decir dar cuenta de cómo la militancia se convierte silenciosamente en una rutina que ocupa uno o varios días de su semana, una determinada cantidad de horas traducidas en actividades y tareas específicas. En otras palabras, pasa a ser parte de la cotidianeidad del individuo como una esfera más de su vida. Nos fuimos preguntando entonces ¿Qué factores y actores intervinieron en el fortalecimiento de la continuidad de la militancia?, ¿qué mecanismos promueve la organización para mantener a sus militantes? Y sobre todo ¿cómo es vivida esta etapa por los y las jóvenes?

Entendemos la construcción de la rutina como una forma de estabilización de la militancia, dado que nos permite imbuirnos en los procesos donde se van fijando prácticas ligadas a modos de militar, tiempos para llevarlas adelante de manera más sistematizada de acuerdo o en respuesta a la dinámica de la propia organización. Identificamos la figura de la "orgánica”, en sus diferentes variantes, como factor central actuando en los procesos de internalización de las estructuras de autoridad, liderazgos, valores e identidad política. En esta etapa observaremos las prácticas de los actores reforzando lógicas de funcionamiento propios de las fuerzas políticas.

Al pensar el proceso de estabilización de la rutina dialogamos con una serie de autores que nos ayudaron a repensar ese momento, encontramos, en principio, la definición de hábitos por parte de Berger y Luckman (2003), quienes con el fin de comprender las causas de la aparición, subsistencia y transmisión de un orden social explican que

Toda actividad humana está sujeta a la habituación. Todo acto que se repite con frecuencia crea una pauta que luego puede reproducirse con economía de esfuerzos y que ipso facto es aprehendida como pauta por el que la ejecuta. Además, la habituación implica que la acción de que se trata puede volver a ejecutarse en el futuro de la misma manera y con idéntica economía de esfuerzos (Berger y Luckmann, 2003, p.72).

No obstante, esta operación hasta casi mecánica que nos proponen los autores, tenemos que considerar que cada uno de los actores, trae consigo uno o varios repertorios de acción -en algunos casos heredados, en otros aprendidos e incorporados en diversas experiencias de participación anteriores- que ponen en diálogo con su práctica política en los espacios (Lahire, 2004). A su vez, la configuración de una rutina en una agrupación política suma otros condimentos y particularidades en donde se objetivan las lógicas de funcionamiento del espacio, como ser roles de autoridad y jerarquías (Sawicki, 1997; Offerlé, 2004, 2011; Fretel, 2011).

En ese sentido, atendiendo a la diversidad de las agrupaciones, la "orgánica" nos permitió distinguir la estabilización de la militancia en una rutina de acuerdo con el ordenamiento interno de las organizaciones, sus estructuras dirigenciales, líneas de acción y valores. Es decir, posiciona a los y las militantes no solo en un esquema organizativo 
con respecto a la planificación y realización de las acciones de acuerdo a una línea política mayor, sino que también las y los ubica en una línea de jerarquías y roles de autoridad a quienes deben reconocer y seguir como condición fundamental para que la práctica política se lleve adelante. Indagaremos, en principio, sobre los significados que adquiere la noción para ver más adelante cómo influye en la construcción de la rutina.

Reconocemos a la "orgánica” como un término común en la jerga de la militancia político partidaria y de acuerdo con el registro de las entrevistas notamos que cuando los y las militantes aluden a ella se desprende un halo de autoridad del término. Es así que al focalizar nuestra atención se observan algunas variantes, en tanto es utilizada como sustantivo y también como adjetivo. En el primer caso, se refiere por un lado a la "carta orgánica" del partido, por otro a la "estructura" y finalmente a la "conducción política". En cierto modo, los tres conceptos nos muestran distintos niveles de organización y autoridad dentro de la agrupación, pero ya veremos con diferente relevancia.

La primera se corresponde con las normas y estatutos escritos que dejan explícitas las reglas de funcionamiento del espacio adecuándose al sistema político mayor. Sin embargo, se advierte que más allá de que las y los jóvenes den cuenta de la existencia y conocimiento de la misma no la evidencian con una fuerte presencia en las prácticas cotidianas. Incluso es de notar cierta vaguedad al momento de referirse a la misma, como lo cuenta Elena, ${ }^{9}$ militante de ACHA de 30 años, quien alude a la carta orgánica como un "librito que escribió Ruiz Palacios ${ }^{10}$ en su momento, sobre el Chaco y sobre el partido"y al momento de mostrarlo dimos cuenta que se trataba del estatuto del partido. ${ }^{11}$

No obstante, en momentos específicos, la normativa se vuelve relevante, por ejemplo, cuando algún o alguna de sus integrantes aspira a ocupar un cargo orgánico, aparece el reglamento. Entonces los requisitos y condiciones como la edad y la antigüedad en el espacio se vuelven importantes y más cuando hay disputas de por medio (Petitfils 2007; Palmeira, 2003: Pedrosa, 2011; Heredia, 2003). A su vez, la condición de ser "afiliado", de acuerdo a cómo lo dictamina la norma para ser considerado un integrante oficial de la agrupación es central durante las épocas electorales. Como describe Raúl, militante de 25 años del PO, "Nosotros primero comenzamos a militar y no tenemos en cuenta lo de la afiliación, recién se nos viene a la cabeza cuando la justicia electoral nos pide la legalidad o cierto número para renovar esa legalidad". Este último aspecto para los partidos más chicos es crucial dado que, de acuerdo a las exigencias del sistema de partidos, ${ }^{12}$ hay un mínimo que cumplir. Por lo tanto, estos requisitos que dicta la “orgánica” para agrupaciones, como el PO, se vuelven una cuestión de supervivencia.

${ }^{9}$ Los nombres de las personas entrevistadas fueron modificados.

${ }^{10}$ Militar y político de origen cordobés, fue Subsecretario de Asuntos Institucionales del Ministerio del Interior de la Nación durante la última dictadura cívico militar y posteriormente fue nombrado como gobernador de facto de la provincia del Chaco por el período 1981-1983. Fundador y líder de ACHA, partido con el cual logró ser intendente de Resistencia y diputado provincial y nacional.

${ }^{11}$ Nos referimos a la Carta Orgánica y la Declaración de Principios del Partido.

${ }^{+2}$ De acuerdo con la Ley Orgánica de Partidos Políticos $N^{\circ} 23.298$ para poder funcionar deben acreditar "la afiliación de un número de electores no inferior al cuatro por mil (4\%) del total de los inscriptos en el registro de electores del distrito correspondiente, hasta el máximo de un millón (1.000.000), acompañadas de copia de los documentos cívicos de los afiliados donde conste la identidad y el domicilio, certificadas 
Campusano. Entre la rutina, el cambio y la transición: El involucramiento político en la militancia juvenil de...

La "conducción”, por su parte, se encuentra vinculada con la "orgánica” porque a partir de ella se delimita la línea política que rige para la agrupación y que luego tiene incidencia directa en la "estructura orgánica". Está constituida por los y las "referentes" del espacio, quienes son la autoridad máxima del mismo. A su vez, podemos identificar diferentes jerarquías, por ejemplo, en el caso de La Cámpora la conducción está a cargo de la expresidenta Cristina Fernández, como lo explica Martín, militante de LC de 28 años, "nosotros tenemos una sola conducción que es Cristina, el resto tenemos responsabilidad política”, refiriéndose al rol de "responsable político" que en su caso ocupaba al momento de la entrevista. Es decir, en un orden local, a esa línea de autoridad la continúan conducciones intermedias: "en las provincias hay equipos de trabajo, con conducciones intermedias, con los que se milita en los territorios". Esa ingeniería que se despliega, da cuenta del entramado de roles con más peso en la agrupación - "conducción” y "conducciones intermedias"-, por donde circulan y se definen las decisiones políticas. Este ordenamiento define internamente líneas de autoridad y una división del trabajo político que va marcando entre unos y otros militantes el crecimiento de una burocracia interna y de la profesionalización de quienes ocupan roles de mayor jerarquía (Offerlé, 2004).

A su vez, en el caso de aquellas organizaciones, como en el radicalismo, donde existen varias líneas internas, ${ }^{13}$ reconocer la "conducción política" implica no solo enmarcarse bajo esa línea de autoridad sino también poder distinguir cómo los y las líderes capitalizan los espacios de poder que ocupan al momento de definir las acciones de la agrupación. De esta manera, deja al descubierto las tensiones y disputas que dan forma a la red de relaciones en las que deben intervenir los y las militantes. Blanca, una estudiante de Gestión Cultural en la Universidad Nacional del Nordeste (UNNE) de 29 años que milita en la JR, explica que el líder de la línea interna es central al momento de definir los ejes de acción de acuerdo con la distribución de programas y políticas públicas nacionales,
“Acá es simple, si Ángel Rozas dice para dónde tiene que ir el programa se agarra. Rozas tira todo para Convergencia y lo que resta al NEA y Somos Parte, o sea programas, porque hay cosas que si o si tienen que llegar a los municipios desde nación y ahí ya se encarga la intendencia. Pero justamente como Rozas es el que digita, hay muchos choques en la intendencia en Barranqueras porque ellos son de Somos Parte, entonces el grueso de programas que realmente son buenos vienen a Convergencia, pero eso es porque está él arriba como Jefe del interbloque". ${ }^{14}$

por autoridad partidaria".

${ }^{13}$ Al momento del trabajo de campo el partido en la provincia presentaba tres líneas internas: Convergencia Social liderada por el exgobernador Ángel Rozas; Somos Parte liderada por el exgobernador Roy Nikisch, la intendenta de Barranqueras Alicia Azula y el intendente de Sáenz Peña Gerardo Cipolini; y Nuevo Espacio Abierto (NEA) liderado por la ex intendenta de Resistencia Aida Ayala.

14 Ángel Rozas fue elegido como presidente del Bloque de la UCR en el senado y también fue presidente 
Al decir de Rosato (2003), las líneas internas no son solo grupos diferenciados al interior del partido sino que "cortan" la organización formal incluyendo el territorio y los diferentes sectores que componen el partido, dejando en evidencia de un lado y del otro a las figuras, sus recursos, intereses y militantes. A partir de la explicación de Blanca, esa delimitación queda expuesta, con un fuerte énfasis en las acciones que el conductor, en este caso, lleva adelante para posicionar su línea por sobre las demás. La delimitación de la rutina implica lograr esta comprensión sobre el funcionamiento de las líneas internas, ayuda a que los y las militantes puedan moverse en la organización como parte de la dinámica política interna, en vez de sentirse como en un campo minado.

Finalmente, el otro término que se desprende de "la orgánica" es la "estructura orgánica" la cual alude al esquema organizacional que adopta la agrupación a nivel interno y va a marcar su modo de funcionamiento. Es decir, las diferentes jerarquías que se identifican, las áreas o secretarías en las que se divide y los planes de acción para cada una de ellas; este es uno de los factores más presentes en la configuración de una rutina militante. El armazón que se delimita establece un organigrama compuesto por las y los responsables de cada una de las áreas que, de acuerdo con las agrupaciones y su esquema interno, tienen nombres diferentes para cada rol: será "Presidente de la Juventud" y "referente" de cada área para la Juventud Radical y de Acción Chaqueña; "Responsable político” y "responsables” por áreas y secretarías para La Cámpora, y "Referentes de círculos" y "frentes" en el Partido Obrero. Esta estructura dispone el campo de acción de la agrupación, visibiliza sus frentes y objetivos principales y la forma de actuar en él, como expresó Lucas, militante de 28 años de LC, "la estructura orgánica te ordena la militancia”.

Soledad es militante de LC de 33 años y al momento del trabajo de campo pasó por roles que la llevaron a ocupar un mayor protagonismo en la agrupación, no solo en la ciudad sino también a nivel provincial. Su trayecto en la agrupación estuvo marcado por ser "responsable" de secretarías, principalmente la de Formación, ${ }^{15}$ al igual que por fuera de la agrupación se desempeñó coordinando programas nacionales como Conectar Igualdad. ${ }^{16}$ Por lo tanto, lo que nos cuenta lo hace en tanto figura que tiene protagonismo

del interbloque Cambiemos, integrado por el partido centenario y el PRO, hasta septiembre de 2017.

${ }^{15}$ La Secretaría de Formación de LC se ocupa de dar talleres, cursos y actividades que tienen por objetivo discutir y difundir internamente las posiciones del colectivo y sus lineamientos políticos ya sean coyunturales o históricos.

${ }^{16}$ Es un programa surgido durante la segunda gestión del gobierno de Cristina Fernández lanzado en el año 2010 -decreto $\mathrm{N}^{\circ} 459 / 10$. La iniciativa está enfocada en recuperar y valorizar la educación pública, con el fin de reducir las brechas digital, educativa y social en el territorio argentino. Fue una política en la que intervinieron la Presidencia de Nación, la Administración Nacional de Seguridad Social, la Jefatura de Gabinete de Ministros, el Ministerio de Educación y el Ministerio de Planificación Federal e Inversión Pública y Servicios.

El programa actualmente pasó a la órbita del Ministerio de Educación, Cultura, Ciencia y Tecnología, en el marco del Plan "Aprender Conectados", tras haber sido transferido a la órbita de las provincias en 2016 por el gobierno nacional y las mismas no cuentan con fondos para solventarlo. En 2016, el gobierno desmanteló el Plan Nacional de Inclusión Digital Educativa (Pnide), la pata pedagógica del programa de distribución de computadoras a los alumnos de escuelas públicas. En 2017, recortó parte de su presupuesto. En 2018 volvió a realizar despidos, reduciendo en un $43 \%$ sus fondos. 
Campusano. Entre la rutina, el cambio y la transición: El involucramiento político en la militancia juvenil de...

y autoridad dentro del espacio y por su recorrido brinda una mirada más programática sobre "la orgánica".

"nuestra organización tiene una particularidad, que tiene que ver
con esa estructura orgánica de funcionamiento porque permite
organizar a la militancia en función de determinados objetivos
y propósitos (...) Nosotros entendemos que para que la política
exista tiene que haber una orgánica, un orden, tiene que haber una
planificación, tiene que haber una sistematización de qué hacemos
y porqué lo hacemos, para eso es necesario que un compañero
o compañera se ocupe y sea el responsable de garantizar que lo
que se planifica o lo que se diseña se pueda plasmar y en función
de eso, la construcción es colectiva, las planificaciones, las
organizaciones, la acción o la actividad en sí siempre es colectivo.
Las decisiones muchas veces pasan por el responsable o la
responsable política pero los procesos son colectivos".

Emerge de sus palabras la idea de "estructura orgánica" en tanto esquema operativo que delimita una división de tareas y roles, donde se identifican rangos y responsabilidades acordes con esa posición. Está claro que el proceso colectivo al que hace referencia tiene que ver con la implementación que dispone la "estructura”, mientras que las instancias de decisión pasan necesariamente por los o las "responsables".

No obstante, la incorporación de este esquema no se da de manera armónica sino que genera ciertos conflictos y marca dificultades, como nos cuenta Carlos militante de 28 años de LC-, su difícil experiencia de adopción de la estructura de la agrupación. Su trayecto de militancia lo tuvo involucrado a la Juventud Peronista que caracteriza como "improvisada", a partir de allí empieza sus primeros trabajos como "becario" de diferentes dependencias estatales hasta llegar a La Pingüina, una agrupación kirchnerista local que nació para "bancar a Cristina”, que luego confluirá en LC. En base a esa experiencia previa cuenta que:

"nos costó muchos adaptarnos a la metodología de La Cámpora... es muy verticalista, en su organización se destaca cómo se distribuyen las funciones para cada compañero. Nosotros en La Pingüina nos organizábamos como podíamos y todos ayudábamos entre todos, pero en La Cámpora era muy distinto porque si vos eras de ese sector, eras de ese sector y con esos compañeros vos te tenías que organizar para llevar a cabo una actividad y después sí comunicarte con las otras áreas, pero te tenías que organizar en tu sector (...) me costó mucho adaptarme porque yo tenía que seguir las órdenes, por así decirlo, del secretario o responsable del área y era muy difícil porque como yo no me entendía mucho con él y por ahí lo quería hacer a mi manera y no era su manera de hacer, entonces era muy complicado". 
Es necesario destacar con respecto a La Cámpora que, de las descripciones de sus militantes, se desprende con gran énfasis su rasgo "verticalista". De acuerdo con Mutuverría (2017), tal condición se explica en base al crecimiento que tuvo la agrupación lo cual demandó una mayor burocracia que organizara una jerarquía a nivel nacional, generando para con sus militantes una serie de "hartazgos". El término constituye una forma de caracterizar el funcionamiento de la orgánica, que, en vinculación con la doctrina peronista, como explica Balbi (2013, p.10), demanda "que los hombres y las organizaciones estuvieran adecuadamente encuadrados... y en este marco tuvieran obediencia, una disciplina inteligente e iniciativa". Todas estas características estaban presentes en el discurso de los y las militantes como atributos demandados en el espacio.

De acuerdo con lo que venimos desarrollando, el "verticalismo", entonces, asegura el funcionamiento de esa estructura orgánica, un esquema de trabajo en base a roles y responsabilidades que deben ser respetados, generando una serie de disposiciones y controles que se extiende hacia la regulación de diferentes frentes del comportamiento militante. No obstante, genera molestias, es por ello que para Carlos la "metodología verticalista" de la organización choca con las formas de militar aprendidas que trae de sus experiencias anteriores, en donde primaba una mayor autonomía sobre la práctica política. Como explica se trataba de un “hacer y decidir en conjunto”. En cambio, en LC necesariamente tenía que adaptarse dentro de un esquema más rígido de funcionamiento en base a una serie de rangos que debe obedecer sin posibilidad de confrontar o negociar otras opciones.

La “estructura orgánica”, como vemos, cumple un papel importante dentro de la estabilización de la militancia en tanto rutina, define un esquema organizativo donde se trasluce la planificación y acciones ajustándose a la línea política del espacio, al igual que demanda el reconocimiento de una línea de jerarquías y roles de autoridad que las y los militantes deben manejar para que la práctica política sea posible.

Ahora bien, la utilización del término como adjetivo, cuando realizan afirmaciones como "somos orgánicos" por ejemplo, nos permite enriquecer el conjunto del análisis que hasta aquí venimos realizando. Es así que "ser orgánico” quiere decir que, en tanto militantes del espacio, reconocen y siguen la línea que esa autoridad -carta, estructura o conducción- dispone. Sin embargo, no se trata del simple acatamiento de una orden sino que veremos diferentes situaciones a las que los y las enfrenta el respeto por la organicidad del espacio.

En el caso de Marcos, estudiante de abogacía de 20 años que milita en la JR, por ejemplo, nos cuenta que, ante la posibilidad de integrar alguna lista, la decisión de cumplir con la orgánica no representa mucho inconveniente, explica que "la cuestión de los cargos públicos creo que es importante tenerla presente, yo en ese sentido soy bastante orgánico, donde el partido me necesite voy a estar, cubriendo el cargo que sea”. Sin embargo, en el universo de las agrupaciones partidarias ser candidato a algún cargo público no se presenta como una decisión problemática a acatar. Veamos entonces, aquellas definiciones que son resistidas y donde los y las militantes pueden marcar sus 
posturas encontrando, más allá del blanco y negro que la organicidad del espacio les reclama, una serie de escalas de grises que definen para lograr ciertos acuerdos.

Retomamos para entender más sobre este punto el caso de los y las militantes de la línea de la Juventud Radical Convergencia Social, quienes se definen como “independientes pero orgánicos". A pesar de la contradicción que esta afirmación parece encerrar, los y las jóvenes explican que pueden ser orgánicos al representar y no traicionar los ideales que el líder dispone pero que encuentran cierta autonomía para poder elegir a qué referentes de las líneas intermedias dan su apoyo. Lo cual les permite negociar con otras figuras del espacio recursos y acciones. En una entrevista grupal con Cecilia, Ramiro y Eliana -militantes de Convergencia Social- explicaron esta forma de "autonomía" que encontraron sin dejar de "ser orgánicos".

-Cecilia: Mas allá de que somos independientes pero muy orgánicos, hoy pertenecemos a un organismo dentro del radicalismo chaqueño encabezado por Ángel Rozas, tampoco hacemos nada que vaya en contra de los principios de Convergencia Social. Somos independientes en el sentido de poder elegir, esto te da libertad de acción de poder decir mañana no me gusta la cara de este, sabemos que va a llegar y se va a olvidar de nosotros y entonces no tenés esa presión de apoyar a alguien que no te gusta. Pero tenemos muchos referentes, que hoy están ocupando una banca en el Concejo o en la Cámara de Diputados que también nos apoyan.

-Ramiro: Y te dan respuestas.

-Cecilia: Tampoco es que somos tan rebeldes y no hacemos nada. -Ramiro: Nosotros por ahí, sin dar nombres, apoyamos algunos candidatos. El día que llegaron, ellos solos nos dijeron 'bueno chicos yo necesitaría a alguien en mi oficina', entonces también podemos ayudar a los chicos que están sin trabajo a que tengan un ingreso.

-Eliana: Nos juega a favor y en contra. A favor en el sentido que te llaman, pero después a la hora de la financiación es el problema.

-Ramiro: Y tenés los dirigentes que se ponen en contra justamente porque no somos obedientes.

Es necesario dejar en claro que durante el tiempo que abarcó, no solo el trabajo de campo sino la línea temporal de desarrollo de los itinerarios de los y las jóvenes protagonistas de esta investigación, la línea Convergencia Social no se encontró vinculada a ninguna gestión de gobierno y por lo tanto con recursos limitados en la práctica política, teniendo como principales referentes algunos y algunas legisladoras provinciales y a Ángel Rozas, pero con muy poco nivel de influencia y llegada para con la rama juvenil. De esta forma, comprendemos que ser orgánico refiere a la obediencia indiscutida al líder, en este caso Ángel Rozas. Sin embargo, dadas las condiciones 
limitadas en la que se encuentra la Juventud de la línea, la obediencia a las figuras intermedias se negocia en función de los recursos que se presenten en disputa.

Por su parte Laura, militante de 28 años de LC, explicó a través de una anécdota que seguir la orgánica más allá de los ruidos que en lo personal le generaba, se trataba de decisiones que se respetaban en función de la coherencia de la agrupación. Ella, al igual que varios de sus "compañeros", no estaban muy de acuerdo con Daniel Scioli ${ }^{17}$ como candidato presidencial en 2015. Cuenta que tuvieron "acaloradas" discusiones al interior del grupo, pero que, a partir del lema en el que se alineó la agrupación - "el candidato del proyecto"-, de cierta manera se resolvió la discusión: "teníamos que sostener el modelo, nuestro desvarío ideológico no tenía lugar, no es como que cambió mucho mi opinión, pero sé dónde puedo expresarla”. Laura se desdobla en esta afirmación dejando en claro que su parte militante es la que se impone más allá de las dudas personales. La militante no tiene objeción hacia el candidato de su organización, sino que milita por él.

No es casualidad que en este apartado nos hayamos centrado principalmente en la Juventud Radical y La Cámpora, dado que de los casos con los que trabajamos son las agrupaciones más grandes en relación a cantidad de militantes y afiliados. Se encuentran vinculadas con gestiones de gobierno lo cual les permite tener referentes ocupando posiciones centrales en organismos del Estado. De esta forma, les brindan no sólo una estructura económica sino espacios de poder e influencia política. Se trata, además, de fuerzas pertenecientes a tradiciones políticas históricas en la provincia. Estos también son factores a tener en cuenta al momento de indagar en la "orgánica" y sus diferentes significaciones de acuerdo con las agrupaciones.

En esta sección, revisamos la influencia que la “orgánica”, en sus diferentes formas, tiene en los procesos de construcción de rutinas militantes y su contribución al afianzamiento de la práctica política dentro de un espacio, lo que nos permite evidenciar una mayor experiencia en el recorrido por parte de los y las jóvenes. No se trata solo de ir y militar en determinada agrupación sino de reconocer esquemas de autoridad, líneas jerárquicas en función de una identidad e historia política que definen las diferentes dimensiones que adquiere esa agrupación y lo que implica desenvolverse como militante en ella. Al recorrer el proceso, observamos que para los y las jóvenes significaba descubrir, más allá de la continuidad de la estructura y funcionamiento de la propia agrupación, el afianzamiento de sus intereses y el sentido de pertenencia al espacio. Las actividades que llevan adelante las y los interpela como militantes, proceso que disfrutan y afianzan como un "estilo de vida".

\section{Los hitos del crecimiento político}

Desde la perspectiva teórica que adoptamos, el análisis del compromiso político lo asumimos como un fenómeno variable a la vez en intensidad y en duración,

${ }^{17}$ Es un político argentino, fue vicepresidente del país durante 2003-2007 y luego gobernador de la provincia de Buenos Aires durante 2007-2015. Fue candidato a presidente de la nación en las elecciones de 2015 que pierde contra Mauricio Macri. 
Campusano. Entre la rutina, el cambio y la transición: El involucramiento político en la militancia juvenil de...

que evoluciona en función de factores contextuales y situacionales, ya sean de orden social, institucional o individual (Becker, 1960; Fillieule, 2015). Hasta aquí, fuimos reconstruyendo la evolución del involucramiento desglosando el rol de la "orgánica" en la configuración de una rutina. Ahora, abordaremos ciertos momentos de cambio en los itinerarios que develan los movimientos en la experiencia de militancia política en clave generacional.

Al analizar el movimiento en los itinerarios observamos que se produce de diferentes formas, cuando los y las jóvenes exponen las instancias importantes de su recorrido se refieren a momentos clave, entonces para abordarlos dando cuenta de tales variantes proponemos la categoría hitos de transición. En principio, al momento de abordar la dimensión temporal desde los enfoques biográficos, Godard (1996), quien estuvo abocado a los estudios de trayectorias e historias de vida, recupera el sujeto identificando acontecimientos que constituyen "nudos o puntos de bifurcación" en sus recorridos que pueden cambiar su destino. Sin embargo, el autor hace referencia a aquellos hechos de carácter "inesperado", propios del trayecto vital de los individuos. A su vez, indagamos en la noción de acontecimiento, la cual se refiere a los hechos y las características en función a las coordenadas espaciales y simbólicas que implica una transformación de lugares, es decir una redefinición de los códigos sociales (De Certau, 1995).

Tales lecturas nos sirvieron para delimitar el término hito, al cual entendemos profundizando la idea de un acontecimiento en sí mismo, vinculándolo con momentos o hechos que nos ayudan a comprender procesos de cambio en la construcción del compromiso que evidencian marcas producto de la militancia política en clave generacional. Los proponemos como hitos de transición porque señalan el paso hacia una nueva posición ya sea objetiva, subjetiva o ambas. Los hitos sirven a modo de fotografías a través de las cuales nos detenemos a observar y analizar los momentos de evolución en el involucramiento con el espacio político y la propia militancia que, como veremos, de acuerdo a las organizaciones irán tomando diversos matices.

Agrupamos los hitos de la siguiente manera: (a) Hitos simbólico-identitarios, que se refieren a hechos que realimentan la identidad y posicionamiento en el espacio político; (b) Hitos de la dinámica política, vinculados a eventos propios del ritmo y funciones de las organizaciones político partidarias, y (c) Hitos del trayecto, se relacionan con sucesos que el tránsito de la propia militancia va generando.

(a) Hitos simbólico-identitarios: se trata de hechos que responden al dinamismo político y social del contexto histórico ya sea internacional, nacional o local. Por ejemplo, el conflicto entre el gobierno con el campo en $2008,{ }^{18}$ la muerte de Néstor Kirchner en

\footnotetext{
${ }^{18}$ El conflicto con el campo se refiere a la serie de disputas que generó la decisión del Gobierno de Cristina Fernández de aplicar por decreto -Resolución no 125/2008- un sistema de retenciones móviles a las exportaciones agropecuarias -la soja, el trigo y el maíz- que provocaron protestas y medidas de fuerza por parte de las entidades que agrupan a los productores del sector. Las medidas incluyeron el bloqueo de rutas a lo largo del país por 127 días, desde el 11 de marzo de 2008 hasta el 18 de julio.

Al conflicto se le sumó un paro de los empresarios transportistas con bloqueo de rutas que agravó la situación y el abastecimiento de las ciudades. Durante el conflicto, se produjo la renuncia de Martín Lousteau. El 17 de junio, la presidenta envió la Resolución 125 al Congreso donde fue aprobada por la
} 
2010 o el asesinato al militante del Partido Obrero Mariano Ferreyra ${ }^{19}$ el mismo año. En principio, estos sucesos no se corresponden con la etapa de militancia de los y las jóvenes en las agrupaciones actuales, no obstante, los retomamos porque aparecen en sus discursos reafirmando sus militancias. Actúan a nivel simbólico reforzando valores que apuntalan su práctica política y sobre todo la pertenencia al espacio (Vázquez y Vommaro, 2012).

Un punto que cabe destacar es que estos hitos, a su vez son señalados por otros autores como momentos que marcaron nuevos ciclos de movilización e ingresos a la militancia juvenil (Vázquez, 2009; Vázquez y Vommaro, 2012; Vázquez, Rocca Rivarola y Cozachcow, 2016; Vázquez, Vommaro, Núñez y Blanco, 2017). En nuestro trabajo las referencias se enmarcan en esta lógica debido a que, de acuerdo con las entrevistas, estos hitos los movilizaron a actuar políticamente en algún espacio. En el caso de algunos y algunas jóvenes de La Cámpora, cuyo antecedente más inmediato fue la participación en la organización local Juventud Pingüina, refieren que su creación fue a partir de "la muerte de Néstor" donde el principal objetivo era "bancar a Cristina”. De esta forma, los hechos integran un relato histórico "que les permiten describir la experiencia militante anclada en su propio recorrido biográfico” (Vázquez y Vommaro, 2012, p. 9).

(b) Hitos de la dinámica política, nos referimos a hechos que se encuentran dentro del rango de posibilidades que la dinámica del campo político partidario permite. Existen lógicas que son propias del funcionamiento de tales espacios, que van generando determinados acontecimientos como pueden ser la creación de nuevas líneas internas, las disputas y conflicto ya sea entre las mismas como entre referentes de las agrupaciones, las alianzas y frentes políticos que se constituyen ante momentos electorales, o las victorias o derrotas en las elecciones, por nombrar algunos ejemplos.

Estos momentos son recuperados en tanto dejaron expuestas las lógicas de funcionamiento del espacio, hicieron evidentes las tensiones, las relaciones de fuerza, y las líneas e intereses puestos en juego. Como así también los hicieron visibles en términos de rostros con nombres y apellidos. Las narraciones las evidencian como instancias de aprendizaje o "cimbronazos" que marcaron un "cambio de actitud", o "un antes y un después" y en algunos casos fueron leídos como posibilidades ante las cuales se les abrieron nuevos caminos. Es necesario remarcar que no se trata de momentos o situaciones actuando de manera aislada o que en sí mismos constituyan ejes que generen mayor involucramiento político, sino que a través de ellos podemos dilucidar la puesta en relación de diversos factores actuantes que nos ayudan a entender cómo son significados estos momentos para los y las jóvenes en términos de mayor compromiso dentro de los márgenes partidarios.

Cámara de Diputados, pero finalmente fue rechazada en el Senado por el voto "no positivo" del entonces vicepresidente de la Nación, Julio Cobos.

${ }^{19}$ Mariano Ferreyra era un militante de 23 años de edad que fue asesinado de un tiro en el pecho por un grupo de afiliados a la Unión Ferroviaria, quienes actuaron en complicidad con miembros de fuerzas policiales en una manifestación de trabajadores tercerizados en la que se exigía el pase a la planta permanente en la Línea Roca. 
Rescatamos el episodio de la formación de la línea interna Somos Parte en el radicalismo que cuenta Lorena, bibliotecaria de 33 años militante de la JR. Este hecho, en tanto hito, significó para el grupo de militantes la puesta en evidencia de la disputa entre la y los dirigentes radicales Aida Ayala, Ángel Rozas y Roy Nikisch. ${ }^{20}$ El hito les develó, entre otras cuestiones, que la Juventud Radical que hasta ese momento integraban, en realidad estaba alineada con Convergencia Social, la línea que lideraba Rozas, lo que supuso una nueva dirección marcándoles "otros caminos".

"Veíamos cómo entre los mayores era toda una discordia. En ese entonces lo veíamos como algo conflictivo y tratábamos de mantenernos firmes, pasa que en Convergencia nos decían que éramos el radicalismo, nunca una línea interna, éramos la Unión Cívica Radical y nosotros éramos la Juventud de la UCR, nos manteníamos ahí entonces... Después cuando Convergencia se fue cayendo [al formarse la otra línea se lleva integrantes], tal vez porque fuimos creciendo un poco más y empezamos a ver otros caminos, que había otras alternativas, que había jóvenes que queríamos un poco más de participación que en Convergencia no lo teníamos". (Lorena JR)

La creación de la línea interna marca nuevos límites al interior de la organización, posicionando a los y las militantes en un espacio en disputa, en donde pueden poner en perspectiva de manera más clara sus opciones, es decir, logran clarificar sus intereses y posibilidades de crecimiento. Por su parte, hay un reconocimiento en las palabras de Lorena de su evolución como militante que le posibilitaba "ver" esos "caminos" y significarlos como aperturas hacia oportunidades de mayor protagonismo en el partido.

(c) Hitos del trayecto, se trata de hechos y situaciones que se desprenden como producto del avance de la propia militancia. Como vimos en el desarrollo del artículo, a medida que la actividad política comienza a ser parte de una rutina, es decir está incorporada como un ámbito más de la cotidianeidad del individuo, las tareas ya no son las mismas ni se realizan de igual manera. Damos cuenta que los y las militantes fueron logrando una mayor experiencia y reflexividad en torno a su práctica política, donde se reconocieron como parte de una estructura mayor, y delimitando acciones que les fueron interesando cada vez más.

Estos hitos muestran los diferentes matices que le imprimen las características de las organizaciones. En el caso del Partido Obrero, por ejemplo, al ser una agrupación que tiene pocos militantes "activos", su organización de rotación de frentes les permite experimentar en ámbitos más allá de los cotidianos. Ese fue el caso que nos relató Raúl, periodista de 26 años y militante del PO, quien venía militando en la universidad y tuvo

\footnotetext{
${ }^{20}$ La línea interna Convergencia Social era la única en la UCR liderada por Ángel Rozas. En 2012, después del crecimiento de diversas figuras al interior del partido, quienes le disputaban el liderazgo a Rozas, se crea la línea Nuevo Espacio Abierto que tenía a la cabeza a Aida Ayala, entonces intendenta de Resistencia. Más adelante, las rivalidades internas en la definición de los integrantes de las listas supusieron una nueva división con la creación de Somos Parte en 2013.
} 
que complementarlo con el frente Tribuna Estatal, lo cual lo llevó a dimensionar lo que leía y discutía con sus compañeros a un nivel mucho más real:

"ver lo que implica ser explotado a nivel trabajo, principalmente, es decir en el hospital donde estuvimos más tiempo militando (..,) veíamos cómo el Estado mantiene totalmente abandonada a las personas dándole una miseria, sabiendo sus necesidades y ver esa vulnerabilidad tan palpable (...) en el hospital en las distintas reparticiones veía no solo la vulnerabilidad de las personas, sino la crisis del sistema sanitario, la crisis gubernamental en algo fundamental que es la salud".

En el caso de las agrupaciones vinculadas a gestiones de gobierno, la militancia, siguiendo a Vázquez (2014a), desde, por y para el Estado y en particular para las organizaciones kirchneristas, les brinda la experiencia, como expresó Lucas (LC), de “hacer politica" y "resolver los problemas de la gente”. Es así que dentro de estos hitos encontramos las experiencias de militantes dando respuestas desde las herramientas y posiciones que proporciona el Estado, hecho que los acerca a la política como "gestión". A su vez Pablo, militante de LC de 24 años que se desempeña en el área de Prensa en el municipio de Resistencia, a través de la "territorialización de la política pública" explicaba que podía acercar a los vecinos a sus derechos "conquistados" por la gestión para la cual militaba. Laura (LC), en su caso, le sumaba el componente del compromiso:

"es por ahí lo que la gente no entiende, la 'grasa militante"21 militaba en su espacio de trabajo, le ponía el plus del compromiso, comprometerse con el trabajo, porque era un espacio extendido de mi militancia".

En ese sentido, los capitales militantes les permiten moverse ahora en los roles de gestión estatal, las y los enfrenta a una construcción político-territorial, a la proliferación de demandas, y tensiones internas por la distribución de recursos (Perelmiter, 2010; Vázquez, 2014a, 2015a). Sin embargo, como fue común escuchar en las entrevistas de los y las militantes de esta agrupación el objetivo central era "transformar el Estado". En el caso del radicalismo, comparten algunos rasgos con las otras organizaciones propios de la política en el territorio. Sin embargo, a nivel de discurso el accionar de los y las jóvenes estaba vinculado a la "gestión" como herramienta que les permitía "llegar" y vincularse con los “vecinos". Estas acciones también les mostraban las limitaciones del espacio para la resolución de problemas estructurales. Como cuenta Marcos (JR),

"empezamos a caminar el circuito, lo más usual que llegamos

a hacer era arreglar un foco de la luz que están entre las boca-calles, o había un terreno que había que cortar el pasto

${ }^{21}$ A principios del gobierno de Mauricio Macri, se produjeron una serie de despidos en distintas dependencias estatales. En el contexto de esos procesos, el nuevo Ministro de Hacienda y Finanzas, Alfonso Prat Gay, expresó que el "Gobierno Nacional quiere un Estado sin la grasa de la militancia", cita a la que hace mención irónicamente Laura (LC) en su comentario. 
y conseguíamos quien corte y era otra forma de entrar... pero a veces las necesidades eran otras y lamentablemente la solvencia política no nos acompañaba".

Estos hitos fueron indicando las transiciones a una posición de mayor involucramiento que se fue marcando como una comprensión y conocimiento más amplios, que en muchos casos supuso el cambio hacia un rol de jerarquía o responsabilidad. Sin embargo, en general, significó comprender los rasgos identitarios, las reglas del juego, conocer las caras e intereses detrás de los proyectos, o la decisión de cambiar de ámbito de militancia para encarar otras formas de acción del partido. Principalmente analizamos la experiencia de la militancia como una práctica compartida, no solo de un momento histórico, sino a través de momentos que van atravesando como grupo.

\section{A modo de cierre}

El objetivo del trabajo fue reconstruir y analizar las formas de involucramiento político de los y las militantes jóvenes de agrupaciones político partidarias en la ciudad de Resistencia. La constante fue tratar de comprender los procesos de cambio, cómo se da el paso hacia una práctica política más comprometida, considerando el compromiso como un proceso que se desarrolla en el tiempo, sujeto a los diversos contextos y a las interacciones que despliegan los actores. Con esta motivación, nos distanciamos de las formas de entender el involucramiento político como el seguimiento de una secuencia de postas de mayor jerarquía. Por el contrario, dimos cuenta que supone transformaciones subjetivas en cuanto al mayor conocimiento como comprensión del espacio y su práctica política en él, marcando incluso instancias de contracción del compromiso, de dudas y obstáculos.

Indagamos para ello lógicas más solapadas a través de las cuales consideramos reside el involucramiento con el espacio, desglosamos la construcción de una rutina militante. En ese sentido, señalamos el factor central que cumple la "orgánica", en sus diferentes formas, al momento de inscribir la militancia de los y las jóvenes en los esquemas de autoridad y líneas jerárquicas en función de una identidad e historia de la agrupación. Estos aspectos les permiten comprender lo que implica desenvolverse como militantes en ellas. El afianzamiento de una rutina nos permitió evidenciar una mayor experiencia en el recorrido donde se fueron haciendo evidentes los intereses propios y el sentido de pertenencia al espacio.

El estudio de la militancia juvenil dentro de las agrupaciones partidarias nos permite comprender los procesos de mayor involucramiento, en términos generacionales, de la práctica política. En ese sentido, propusimos los hitos de transición en tanto categoría a través de la cual abordamos los momentos de paso a posiciones de mayor compromiso que nos permitieron evidenciarlo como producto de una militancia compartida y situada. La experiencia a través de los hitos develó las inscripciones identitarias en un ciclo y momento histórico, percepciones y experiencias compartidas al igual que solidaridades y vínculos que sostienen la militancia. 
Para finalizar, cabe destacar que el estudio cobra relevancia al analizar las vinculaciones entre la militancia política juvenil en relación con casos subnacionales que han sido relativamente poco estudiados. Esto resulta interesante porque permite pensar la formación política y los procesos de involucramiento político de acuerdo con tradiciones y espacios partidarios locales, abordando y reconstruyendo los modelos político-ideológicos que apuntalan la construcción de compromisos militantes juveniles.

\section{Referencias bibliográficas}

Agrikoliansky, E. (2001). Carrières militantes et vocation a la morale: les militants de La Ligue Des Droits de l'homme dans les années 1980. Revue française de science politique 51, 1, p. 27-46.

Agrikoliansky, É. (2017) Las 'carreras militantes': alcance y límites de un concepto narrativo. En O. Fillieule et al., Sociologie plurielle des comportements politiques, Presses de Sciences Po (PFNSP), p. 167-192.

Balbi, F. A. (2013). Las concepciones de política como pragmatismos cognitiva y moralmente informados: consideraciones comparativas en torno de algunas prácticas políticas recurrentes entre los peronistas y los radicales. Actas de las VII Jornadas Santiago Wallace de Investigación en Antropología Social.

Becker, H. (1960). Notes on the concept of commitment. American journal of Sociology, 66, 1, p. 32-40.

Becker, H. (2009). Outsiders. Buenos Aires: Siglo XXI.

Berger, P. L. \& Luckmann, T. (2003). La construcción social de la realidad, Vol. 975. Buenos Aires: Amorrortu.

De Certeau, M. (1996). La invención de lo cotidiano (Vol. 1). Mexico: Universidad Iberoamericana.

Fillieule, O. (2015). Propuestas para un análisis procesual del compromiso individual. Intersticios. Revista sociológica de pensamiento crítico, 9, 2, p. 197-212.

Fretel, J. (2011). La sociología de los partidos políticos bajo el prisma de la derecha francesa. Revista de Sociología, 25, p. 55-74.

Godard, F. (1996). El debate y la práctica sobre el uso de las historias de vida en las ciencias sociales. En R. Cabanes \& F. Godard (eds.) Uso de las historias de vida en las ciencias sociales. Bogotá: Universidad Externado de Colombia, p. 5-55.

Goffman, E. (1968). The moral career of the mental patient. The mental patient. New York: McGraw-Hill, p. 226-34.

Heredia, B. (2003). Conflictos y desafíos: luchas en el interior de la facción política. En A. Rosato \& F. Balbi (eds.). Representaciones sociales y procesos políticos. Buenos Aires: Antropofagia-IDES, p. 45-60

Hughes, E. C. (1996). Carrières, cycles et tournants de l'existence. Le regard sociologique, p. 165-173.

Lahire, B. (2004). El hombre plural: los resortes de la acción. Barcelona: Bellaterra. 
Campusano. Entre la rutina, el cambio y la transición: El involucramiento político en la militancia juvenil de...

Mutuverría, M. (2017). Juventudes y participación política. La condición juvenil en el peronismo platense contemporáneo. Tesis doctoral. Buenos Aires: Universidad Nacional de General Sarmiento.

Offerlé, M. (2004). Los partidos políticos. Santiago: Lom Ediciones.

Offerlé, M. (2011). Perímetros de lo político: Contribuciones a una socio-historia de la politica. Buenos Aires: Antropofagia.

Palmeira, M. (2003). Política, facciones y votos. En A. Rosato \& F. Balbi (eds.). Representaciones sociales y procesos políticos, Buenos Aires: AntropofagiaIDES, p. 31-44.

Pedrosa, F. (2011). Políticas públicas y partidos políticos: El peso de las instituciones informales. Definiciones teóricas y un estudio de caso sobre la UCR. Revista Perspectivas de Políticas Públicas, 1, p. 109-132.

Perelmiter, L. (2012). Fronteras inestables y eficaces. El ingreso de organizaciones de desocupados a la burocracia asistencial del Estado. Argentina (2003-2008). Estudios sociológicos, p. 431-458.

Petitfils, A. S. (2007). L'institution partisane à l'épreuve du management'. Politix, 3, p. 53-76.

Pudal, B. (2011). Los enfoques teóricos y metodológicos de la militancia, Revista de Sociología, 25, Universidad de Chile, p. 17-35. Recuperado de: http://www. facso.uchile.cl/publicaciones/sociologia/articulos/25/2501-Pudal.pdf

Rocca Rivarola, D. (2015). Vínculos y formas de la militancia oficialista como un modo de adaptación a las condiciones de fluctuación política en Argentina y Brasil. Revista Papeles de Trabajo (IDAES), 15, 9, p. 170-198.

Rosato, A. (2003). Líderes y candidatos: elecciones internas en un partido político. En A. Rosato \& F. Balbi (Eds.). Representaciones sociales y procesos politicos, Buenos Aires: Antropofagia-IDES, p. 61-79.

Sawicki, F. (2017). Les réseaux du Parti socialiste: sociologie d'un milieu partisan. Paris: Belin. Valenzuela, J. M. (2015). Juvenicidio: Ayotzinapa y las vidas precarias en América Latina. Barcelona: Ned Ediciones.

Vasilachis de Gialdino, I. (coord.) (2007). Estrategias de investigación cualitativa. Barcelona: Gedisa.

Vázquez, M. \& Vommaro, P. (2012). Con la fuerza de la juventud: aproximaciones a la militancia kirchnerista desde La Cámpora. En G. Pérez \& A. Natalucci (comp.) Vamos las bandas. Organizaciones y militancia kirchneristas, Buenos Aires: Nueva Trilce, p.149-174).

Vázquez, M. (2009). La política desde abajo: narrativas militantes de jóvenes desocupados y desocupadas en Argentina. Revista Latinoamericana de Ciencias Sociales, Niñez y Juventud, 1, 7, p. 423-455.

Vázquez, M. (2014). Militar la gestión: una aproximación a las relaciones entre activismo y trabajo en el Estado. Apuntes, 74, 41, p. 71-102.

Vázquez, M. (2015a). Del que se vayan todos a militar por, para y desde el Estado. Desplazamientos y reconfiguraciones del activismo juvenil y las causas militantes luego de la crisis del año 2001 en Argentina. En M. Valenzuela (comp.) El sistema es antinosotros. Culturas, movimientos y resistencias juveniles, México, DF: Gedisa, COLEF y Universidad Autónoma Metropolitana, p. 383-428. 
Vázquez, M. (2015b). Juventudes, políticas públicas y participación. Un estudio de las producciones socioestatales de juventud en la Argentina reciente. Buenos Aires: Grupo Editor Universitario.

Vázquez, M., Rocca Rivarola, D. \& Cozachcow, A. (2016). Fotografías de las juventudes militantes en Argentina. Un análisis de los compromisos políticos juveniles en el Movimiento Evita, el Partido Socialista y el PRO entre 2013 y 2015. En XII Congreso Nacional y V Congreso Internacional sobre Democracia, Rosario: septiembre.

Vázquez, M., Vommaro, P., Núñez, P., \& Blanco, R. (eds.). (2017). Militancias juveniles en la Argentina democrática: trayectorias, espacios y figuras de activismo. Buenos Aires: Ediciones Imago Mundi.

Vommaro, P. \& Larrondo, M. (2013). Juventudes y participación política en los últimos treinta años de democracia en la Argentina: Conflictos, cambios y persistencias. Revista Observatorio Latinoamericano, 12, p. 254-275. 